\title{
Corneal oxygenation: blink frequency as a variable in rigid contact lens wear
}

\author{
Barbara A Fink, Richard M Hill, Leo G Carney
}

\begin{abstract}
Using a micropolarographic system, we measured the responses of six human corneas to nine oxygen exposure conditions: to air (continuous open-eye) with no contact lens in place, and to eight interblink intervals $(1,2,3$, $4,5,6,7$, and 300 s durations) with an oxygen impermeable lens in place. The corneal oxygen uptake rates immediately following each of those conditions were direct indices of tear bulk-flow exchange under a rigid contact lens as an oxygen route. Greatest efficiencies in reducing corneal oxygen demand were associated with the two highest blink frequencies examined (namely, for interblink intervals of $2 \mathrm{~s}$ or less). Even at those frequencies oxygen demands ranging from 4 to 6 times the open-eye, non-wearing, baseline rate for each eye typically occurred, clearly justifying the need for a supplementary oxygenation route, for example, directly through rigid contact lens materials having inherently high oxygen permeabilities.
\end{abstract}

Adequate exchange between the post-lens tear reservoir and outer tear pool of the eye is vital to the physiology of the cornea during rigid contact lens wear. This exchange is required for the efficient clearance of particulate debris such as tear protein coagulates and desquamated epithelial cells and, in particular in the case of extended wear, the restabilisation of the physical characteristics of the post-lens tear reservoir ( $\mathrm{pH}$, osmolality, buffering capacity) on awakening. This is dependent, in time course and relative completeness, on tear bulk-flow efficiency. ${ }^{12}$ In addition, access and elimination of gases (Oxygen influx and carbon dioxide efflux) across the anterior corneal surface must take place at acceptable rates. ${ }^{34}$ Even the most advanced rigid gas permeable lenses fall short of providing the oxygen levels available to the cornea across its tear-epithelial interface during non-wearing, open-eye conditions.

In this study the role of blink frequency in the oxygenation of the cornea via tear bulk-flow during rigid contact lens wear was evaluated. The measurements could also serve as an index to other exchanges associated with rigid contact lens systems, which are directly dependent upon, or are influenced by, bulk-flow movement of tears as well. ${ }^{5-7}$

Ohio State University,

Columbus, Ohio 43210,

USA

B A Fink

L G Carney

Correspondence to: Barbara A

Fink, PhD, College of

Optometry, Ohio State

University, Columbus, Ohio

43210, USA.

Accepted for publication

7 September 1989

Materials and methods

A Clark type micropolarographic electrode was used to measure oxygen uptake rates of the cornea. ${ }^{389}$ The electrode consisted of a platinum
$500 \mu \mathrm{m}$ in diameter, covered with a polyethylene membrane (12.5 $\mu \mathrm{m}$ thick). Calibration of the sensor was achieved by immersing it in air and nitrogen saturated water baths, maintained at $36^{\circ} \mathrm{C}$. When the probe was applied directly to the cornea, the polyethylene membrane served as a small reservoir of oxygen for the cornea. The depletion of oxygen from the membrane during contact with the cornea results in a reduced current output from the electrode. The slope value of the reservoir emptying course (that is, number of seconds for the reservoir oxygen tension to descend from $140 \mathrm{mmHg}$ to 40 $\mathrm{mmHg}$, minus the time constant of the reservoirprobe-recorder system) was used as a quantitative measure of the corneal response to each condition investigated. ${ }^{8}$ Oxygen deprivation of the cornea was manifested as an increased probe reservoir depletion rate (that is, higher $\mathrm{mmHg} / \mathrm{s}$ rate values). Fluorescein examination following probe contact revealed no damage due to the light but steady contact required.

Measurements were made on the right cornea of each of six healthy young subjects (average age: 24 years) after each of three conditions: in the normal open-eye, after the contact lens had been worn under static (non-blinking) conditions for 5 minutes (which is more than 2.5 times the period required to achieve steady state conditions), ${ }^{10}$ and after the contact lens had been worn under dynamic (with blinking) conditions for 5 minutes. The inter-blink intervals used for the dynamic wearing conditions were $1,2,3,4,5,6$, and 7 seconds. Responses to each of the conditions, expressed as probe reservoir oxygen depletion rates in $\mathrm{mmHg} / \mathrm{s}$, were measured eight times for each cornea. All lenses were made of oxygen impermeable polymethylmethacrylate (PMMA) to eliminate the alternative (transmissivity) oxygen route to the cornea, and were designed so that the back central radius of each matched the

TABLE I Subject, corneal, and contact lens characteristics

\begin{tabular}{|c|c|c|c|c|c|}
\hline Subject & $\begin{array}{l}\text { Age } \\
(y r)\end{array}$ & Sex & $\begin{array}{l}\text { Corneal } \\
\text { curvature } \\
(D, \text { degrees })\end{array}$ & $\begin{array}{l}\text { Net corneal } \\
\text { toxicity }(D, \text { axis, } \\
\text { degrees) }\end{array}$ & $\begin{array}{l}\text { Palpebral } \\
\text { aperaturef } \\
\text { (mm) }\end{array}$ \\
\hline 1 & 24 & $M$ & $\begin{array}{l}42 \cdot 50,007^{\star} \\
43 \cdot 12,097\end{array}$ & -0.67, axis 007 & 12 \\
\hline 2 & 25 & $\mathrm{~F}$ & $\begin{array}{l}41 \cdot 62,002 \\
42 \cdot 37,092\end{array}$ & -0.75, axis 002 & $11 \cdot 5$ \\
\hline 3 & 23 & $\mathbf{M}$ & $\begin{array}{l}42 \cdot 50,180 \\
43 \cdot 47,090\end{array}$ & $-0 \cdot 87$, axis 180 & $10 \cdot 0$ \\
\hline 4 & 28 & $F$ & $\begin{array}{l}41 \cdot 87,180 \\
42 \cdot 75,090\end{array}$ & $-0 \cdot 87$, axis 180 & 8.5 \\
\hline 5 & 23 & $\mathbf{M}$ & $\begin{array}{l}43 \cdot 87,180 \\
44 \cdot 25,090\end{array}$ & $-0 \cdot 37$, axis 180 & $10 \cdot 0$ \\
\hline 6 & 24 & $M$ & $\begin{array}{l}41 \cdot 37,179 \\
42 \cdot 37,089\end{array}$ & $-1 \cdot 00$, axis 179 & $11 \cdot 0$ \\
\hline
\end{tabular}
cathode, $25 \mu \mathrm{m}$ in diameter, and a silver anode,

*All lenses were of oxygen impermeable polymethylmethacrylate, and were of uniform design except that the back central radius of each lens was made equal in curvature to the flattest meridian of the particular cornea fitted; overall diameter $=8.80 \mathrm{~mm}$; optic zone diameter $=7.40 \mathrm{~mm}$; axial edge lift $=0.09 \mathrm{~mm}$; centre thickness $=$ $0.14 \mathrm{~mm}$, and back vertex power $=-3.00 \mathrm{D}$ †Maximum vertical extent. 
TABLE II Oxygen uptake rates ( $\mathrm{mmHg} / \mathrm{s}$ ) of six human cormeas immediately following normal open-eye (no lens) conditions, and eight lens wearing (different inter-blink interval) conditions ${ }^{\star}$

\begin{tabular}{|c|c|c|c|c|c|c|c|c|c|c|}
\hline \multirow[b]{2}{*}{$\begin{array}{l}\text { Subject } \\
\text { Column: }\end{array}$} & & \multirow{2}{*}{$\begin{array}{l}\text { No lens } \\
\text { condition } \\
\text { (open eye) } \\
A\end{array}$} & \multicolumn{8}{|c|}{ Lens wearing conditions (seconds between blinks) } \\
\hline & & & $\begin{array}{l}1 \\
B\end{array}$ & $\stackrel{2}{C}$ & $\begin{array}{l}3 \\
D\end{array}$ & $\stackrel{4}{E}$ & $\begin{array}{l}5 \\
F\end{array}$ & $\stackrel{6}{G}$ & $\begin{array}{l}7 \\
H\end{array}$ & $\begin{array}{l}300 \\
I\end{array}$ \\
\hline 1 & $\begin{array}{l}\mathbf{x} \\
\mathrm{SD}\end{array}$ & $\begin{array}{l}4 \cdot 17 \\
0 \cdot 36 \\
8\end{array}$ & $\begin{array}{c}12.96 \\
2 \cdot 74 \\
8\end{array}$ & $\begin{array}{c}18.06 \\
3.00 \\
8\end{array}$ & $\begin{array}{l}19 \cdot 75 \\
3.06 \\
8\end{array}$ & $\begin{array}{c}21 \cdot 38 \\
5 \cdot 58 \\
8\end{array}$ & $\begin{array}{c}22 \cdot 70 \\
3 \cdot 86 \\
8\end{array}$ & $\begin{array}{c}23 \cdot 25 \\
4 \cdot 35 \\
8\end{array}$ & $\begin{array}{c}24 \cdot 72 \\
4 \cdot 31 \\
8\end{array}$ & $\begin{array}{c}29 \cdot 47 \\
5 \cdot 38 \\
8\end{array}$ \\
\hline 2 & $\begin{array}{l}\mathrm{x} \\
\mathrm{SD} \\
\mathrm{n}\end{array}$ & $\begin{array}{l}4 \cdot 30 \\
0 \cdot 31 \\
8\end{array}$ & $\begin{array}{c}16 \cdot 28 \\
4 \cdot 59 \\
8\end{array}$ & $\begin{array}{c}22 \cdot 43 \\
3.92 \\
8\end{array}$ & $\begin{array}{c}24 \cdot 56 \\
2 \cdot 16 \\
8\end{array}$ & $\begin{array}{c}26 \cdot 70 \\
3 \cdot 28 \\
8\end{array}$ & $\begin{array}{c}27 \cdot 04 \\
2 \cdot 89 \\
8\end{array}$ & $\begin{array}{c}26 \cdot 56 \\
3 \cdot 10 \\
8\end{array}$ & $\begin{array}{c}27.98 \\
2.63 \\
8\end{array}$ & $\begin{array}{c}34 \cdot 24 \\
3.06 \\
8\end{array}$ \\
\hline 3 & $\begin{array}{l}\mathrm{x} \\
\mathrm{SD} \\
\mathrm{n}\end{array}$ & $\begin{array}{l}5 \cdot 22 \\
0 \cdot 69 \\
8\end{array}$ & $\begin{array}{c}21 \cdot 82 \\
3 \cdot 81 \\
8\end{array}$ & $\begin{array}{l}27 \cdot 12 \\
2 \cdot 65 \\
8\end{array}$ & $\begin{array}{c}26 \cdot 57 \\
2.53 \\
8\end{array}$ & $\begin{array}{c}27 \cdot 90 \\
4 \cdot 27 \\
8\end{array}$ & $\begin{array}{c}30 \cdot 36 \\
2.66 \\
8\end{array}$ & $\begin{array}{c}29 \cdot 32 \\
1 \cdot 70 \\
8\end{array}$ & $\begin{array}{c}29 \cdot 16 \\
1 \cdot 20 \\
8\end{array}$ & $\begin{array}{c}31.68 \\
1.89 \\
8\end{array}$ \\
\hline 4 & $\begin{array}{l}\mathbf{x} \\
\text { SD } \\
\mathbf{n}\end{array}$ & $\begin{array}{l}4 \cdot 12 \\
0 \cdot 27 \\
8\end{array}$ & $\begin{array}{c}18 \cdot 09 \\
3 \cdot 23 \\
8\end{array}$ & $\begin{array}{c}20 \cdot 74 \\
4 \cdot 43 \\
8\end{array}$ & $\begin{array}{c}20 \cdot 33 \\
1.22 \\
8\end{array}$ & $\begin{array}{c}21.97 \\
1.66 \\
8\end{array}$ & $\begin{array}{c}23 \cdot 55 \\
2 \cdot 58 \\
8\end{array}$ & $\begin{array}{c}24 \cdot 00 \\
3 \cdot 75 \\
8\end{array}$ & $\begin{array}{c}24 \cdot 37 \\
2 \cdot 97 \\
8\end{array}$ & $\begin{array}{c}24 \cdot 97 \\
4 \cdot 19 \\
8\end{array}$ \\
\hline 5 & $\begin{array}{l}\mathbf{x} \\
\mathrm{SD} \\
\mathbf{n}\end{array}$ & $\begin{array}{l}4.59 \\
0.51 \\
8\end{array}$ & $\begin{array}{c}23.91 \\
2.67 \\
8\end{array}$ & $\begin{array}{c}26 \cdot 58 \\
3 \cdot 88 \\
8\end{array}$ & $\begin{array}{c}27 \cdot 23 \\
4 \cdot 45 \\
8\end{array}$ & $\begin{array}{c}26 \cdot 64 \\
3 \cdot 07 \\
8\end{array}$ & $\begin{array}{c}27 \cdot 21 \\
4 \cdot 65 \\
8\end{array}$ & $\begin{array}{c}28 \cdot 46 \\
3 \cdot 38 \\
8\end{array}$ & $\begin{array}{c}27 \cdot 22 \\
3 \cdot 85 \\
8\end{array}$ & $\begin{array}{c}30 \cdot 22 \\
4 \cdot 11 \\
8\end{array}$ \\
\hline 6 & $\begin{array}{l}\mathbf{x} \\
\mathrm{SD} \\
\mathbf{n}\end{array}$ & $\begin{array}{l}4.64 \\
0 \cdot 58 \\
8\end{array}$ & $\begin{array}{c}14 \cdot 74 \\
3 \cdot 87 \\
8\end{array}$ & $\begin{array}{c}18 \cdot 97 \\
3 \cdot 28 \\
8\end{array}$ & $\begin{array}{l}20.08 \\
1.55 \\
8\end{array}$ & $\begin{array}{c}20 \cdot 70 \\
2 \cdot 13 \\
8\end{array}$ & $\begin{array}{c}21 \cdot 44 \\
1 \cdot 35 \\
8\end{array}$ & $\begin{array}{c}22 \cdot 20 \\
1 \cdot 07 \\
8\end{array}$ & $\begin{array}{c}23.09 \\
1.64 \\
8\end{array}$ & $\begin{array}{c}24 \cdot 56 \\
2 \cdot 03 \\
8\end{array}$ \\
\hline Population: & $\begin{array}{l}\mathbf{x} \\
\mathrm{SD} \\
\mathrm{n}\end{array}$ & $\begin{array}{l}4 \cdot 51 \\
0 \cdot 59 \\
48\end{array}$ & $\begin{array}{l}17 \cdot 96 \\
5 \cdot 13 \\
48\end{array}$ & $\begin{array}{c}22 \cdot 32 \\
4 \cdot 89 \\
48\end{array}$ & $\begin{array}{c}23 \cdot 10 \\
4 \cdot 09 \\
48\end{array}$ & $\begin{array}{c}24 \cdot 22 \\
4 \cdot 49 \\
48\end{array}$ & $\begin{array}{c}25 \cdot 38 \\
4 \cdot 32 \\
48\end{array}$ & $\begin{array}{c}25 \cdot 63 \\
3.99 \\
48\end{array}$ & $\begin{array}{c}26 \cdot 09 \\
3.57 \\
48\end{array}$ & $\begin{array}{c}29 \cdot 19 \\
4 \cdot 93 \\
48\end{array}$ \\
\hline
\end{tabular}

^All lenses were of oxygen impermeable polymethylmethacrylate (PMMA) material.

flattest meridian of the cornea on to which it was fitted. In all other ways the lenses were of identical design. Table I gives the subject, cornea, and lens parameters for the study.

\section{Results}

Table II gives, in absolute units, the oxygen uptake values (in probe reservoir depletion rates, $\mathrm{mmHg} / \mathrm{s}$ ) observed for the six corneas for the normal open-eye and immediately following the static wearing condition and seven dynamic wearing conditions. It can be seen that the rates of oxygen uptake which the cornea showed when released from the oppressive effect of the contact lens increased as the inter-blink intervals became longer and they were at a maximum after static wear of the contact lens. The mean uptake rate and standard deviation found for each condition

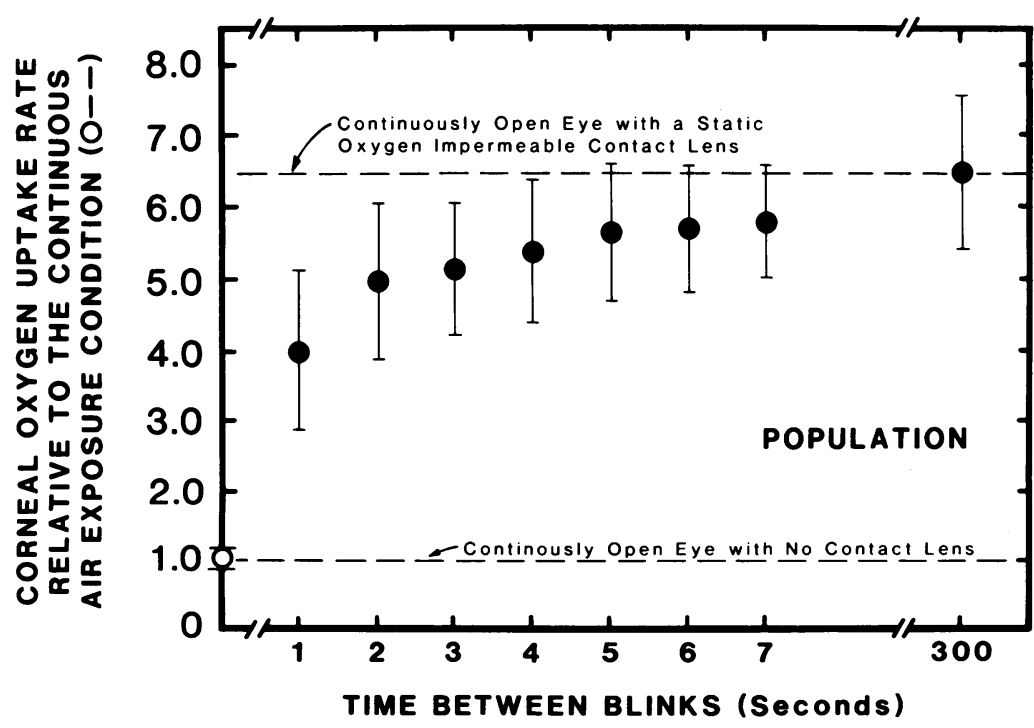

Figure 1: The mean corneal oxygen uptake rates of six human eyes, relative to the mean nonwearing open-eye condition (1.0, open point), associated with each of eight lens wearing blin series of inter-blink intervals ranging from 1 to 7 , and 300 seconds (closed points). The lenses (polymethylmethacrylate) at the thickness used $(0.14 \mathrm{~mm})$ permitted negligible oxygen passage through the material itself. Each point is the mean of 48 measurements, eight on each of the six corneas represented. One standard deviation above and below each mean is indicated. are given (Fig 1) for each subject and for the combined data from all subjects (that is, the composite population based on a total of 48 measurements for each of the nine conditions).

Figure 2 compares the difference in oxygen demand observed for each of these six corneas relative to the mean performance of the composite population over that spectrum of inter-blink intervals from 1 to 300 seconds.

Figure 3 summarises those ranges of interblink intervals over which corneal oxygen uptake values following each experimental condition were not found to be significantly different from each other by the Fisher least significant difference test ${ }^{11}(p=0.05)$ within the population model shown in Figure 1.

Table III is the summary of correlations found between the non-stress baseline values from column A of Table II versus each of the interblink interval responses, seen in columns B through $\mathbf{H}$ for each subject. Also shown are the parallel correlation values for each subject between their inter-blink interval responses, columns $\mathrm{B}$ through $\mathrm{H}$, and their responses to the maximum stress condition, column I of Table II.

\section{Discussion}

As can be seen in Table II, a range of oxygen demands exists among individual corneas. The probe reservoir depletion rates observed here for the non-lens-wearing open-eye condition extended from a high of $5.22 \mathrm{mmHg} / \mathrm{s}$ (subject 3) to a low of $4.12 \mathrm{mmHg} / \mathrm{s}$ (subject 4 ). The most demanding cornea thus displayed a rate which was $27 \%$ greater than that of the least demanding under normal open-eye conditions. The presence of a range of demand among corneas is in agreement with earlier reports. ${ }^{12}$

Corneas also differed in the maximum oxygen uptake rates they displayed, which in all cases were found after the static lens-wearing conditions. The highest mean rate was $34.24 \mathrm{mmHg} / \mathrm{s}$, observed for subject 2 . This represented a nearly 8 times increase over the non-stress (normal, open-eye) demand level found for that same cornea. In contrast, the cornea of subject 6 showed a maximum mean rate of $24.56 \mathrm{mmHg} / \mathrm{s}$, or an increase of only 5.3 times that same cornea's open-eye mean uptake rate. This intersubject variability was statistically significant (ANOVA, $F_{5431}=9.74, p<0.001$ ). Subsequent post-hoc comparisons showed that subjects 1,4 , and 6 were statistically different in their overall demand profiles from subjects 2,3 , and 5 .

In Table III correlation coefficients (and their statistical significance) between oxygen uptake rates are given, firstly, for the non-stress (no lens, open-eye) condition and that following lens wear at each inter-blink interval from 1 to 7 seconds (48 data pairs per correlation value); and, secondly, for the maximum stress (static contact lens wear for 300 seconds) condition and that for each inter-blink interval (also 48 data pairs). These results show that the maximum stress responses of these corneas were more highly predictive of an overall inter-blink demand profile greater or less than the population average than were the non-stress, open-eye (baseline) demand levels. 


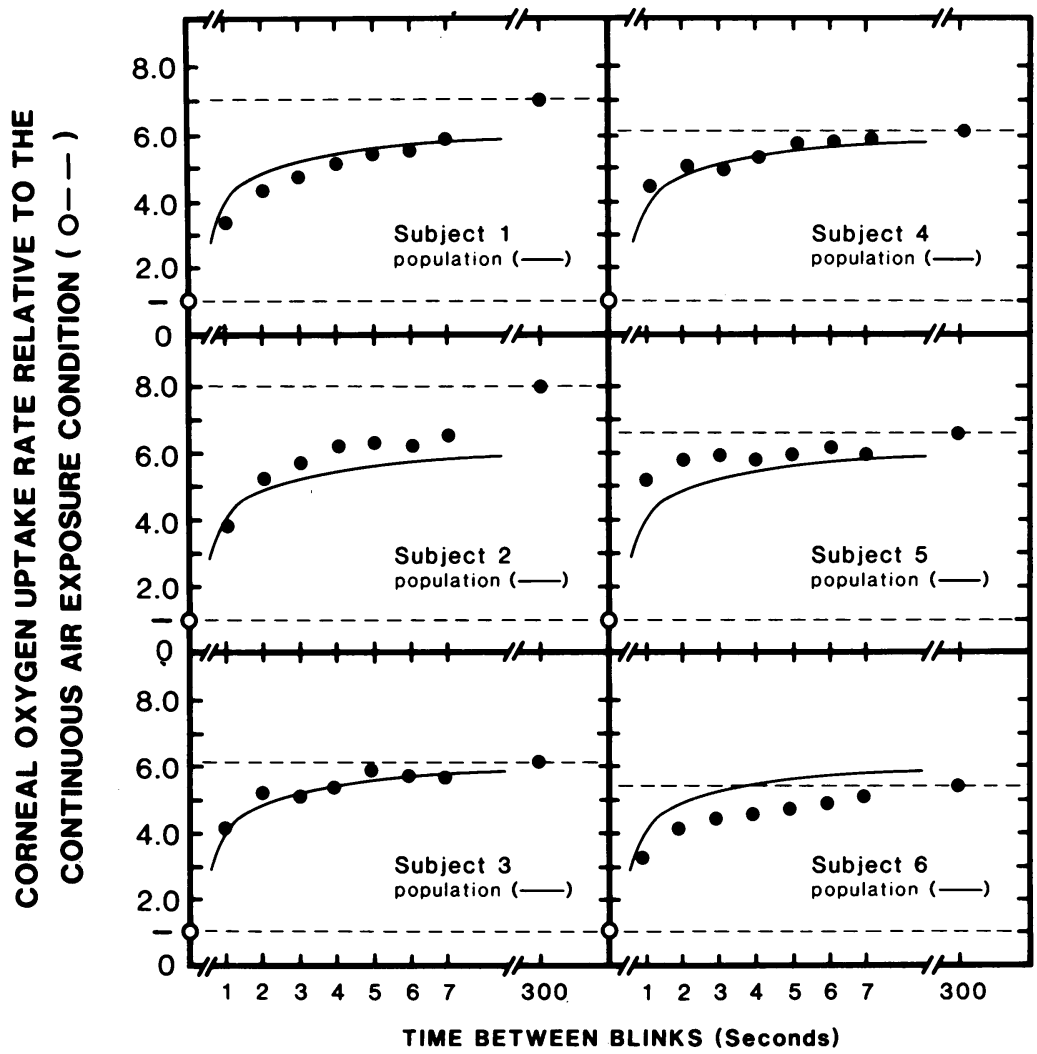

Figure 2: A comparative summary for each of six human cormeas, showing their individual oxygen uptake rates associated with each of eight lens-wearing inter-blink intervals (ranging from 1 to 7 , and 300 seconds (closed points)), relative to the non-lens-wearing open-eye demand for the population $(1 \cdot 0$, open point). The best fitted curve of mean responses for the entire population (based on the closed point means in Fig 1) is shown in each frame as well. Each closed point is the mean of eight measurements; the open point is the mean of 48 measurements. The lower dashed lines represent the relativised oxygen uptake rates for the continuously open eye with no contact lens in place for each subject. The upper dashed lines similarly represent the relativised oxygen uptake rates for the continuously open eye with a static oxygen impermeable contact lens in place.
TABLE III Correlation between oxygen demands following contact lens wear with inter-blink intervals from 1 to 7 seconds, and the two limiting conditions of non-stress ${ }^{\star}$ and maximum stress. $t$

\begin{tabular}{|c|c|c|c|c|}
\hline \multirow{2}{*}{$\begin{array}{l}\text { Inter-blink } \\
\text { Interval } \\
\text { (seconds) }\end{array}$} & \multicolumn{2}{|l|}{$\begin{array}{l}\text { Non-stress, } \\
\text { open eye }\end{array}$} & \multicolumn{2}{|c|}{$\begin{array}{l}\text { Maximum stress, } \\
\text { static lens wear }\end{array}$} \\
\hline & $\begin{array}{l}\text { Correlation } \\
\text { coefficient }\end{array}$ & Significance & $\begin{array}{l}\text { Correlation } \\
\text { coefficient }\end{array}$ & Significance \\
\hline 1 & 0.324 & 0.024 & 0.251 & 0.082 \\
\hline 2 & 0.339 & 0.018 & 0.491 & $<0.001$ \\
\hline 3 & 0.483 & 0.001 & 0.611 & $<0.001$ \\
\hline 4 & 0.419 & 0.003 & 0.589 & $<0.001$ \\
\hline 5 & 0.494 & $<0.001$ & 0.706 & $<0.001$ \\
\hline 6 & 0.415 & 0.003 & 0.684 & $<0.001$ \\
\hline 7 & 0.373 & 0.009 & 0.747 & $<0.001$ \\
\hline
\end{tabular}

*Contributing response values to the means in columns B through $\mathrm{H}$ of Table II versus those values contributing to the means in column I, for each of the six subjects. +Contributing response values to the means in columns $B$ through $H$ of Table II versus those values contributing to the means in column $I$, for each of the six subjects.

lower oxygen demand following contact lens wear. Inter-blink intervals of 2 seconds or longer, however, were found to produce more gradual increases in demand, the performance levels over increasingly wider ranges of intervals not being found significantly different from one another (Fig 3). Corneal oxygen demand then is relatively insensitive to an increase of the interblink period beyond the population average of about 4.78 seconds. ${ }^{13}$ Conversely, a decreasing inter-blink period below that average can significantly diminish the resultant corneal oxygen demand, making clinical attention to adequacy of blink action of importance, particularly for physiologically marginal tear exchange cases.

Tear bulk-flow exchange as an oxygen route to the cornea under rigid contact lenses is, as expected, most efficient at the higher blink frequencies (that is, for inter-blink intervals of 2 seconds or less). Nevertheless, while corneal oxygen demands associated with inter-blink intervals of 2 through 7 seconds were all found to be significantly different from those for the static (no blinks for 300 seconds) wearing case (Fig 3), they were still typically 4 to 6 times greater than the normal open-eye (non-wearing) baseline demands observed.

Corneal oxygenation during rigid contact lens wear can be maximised by three strategies now in common practice: (1) the use of comfortable but mobile lens designs; (2) the encouragement of highest blink frequencies (that is, shortest interblink intervals); and (3) the provision of a supplementary route for oxygen to the cornea through the use of oxygen permeable materials in rigid lenses. While such materials, with the exception of pure silicone elastomer, do not as yet have oxygen transmissivities to return corneal oxygen demands to non-wearing levels, the reduction in corneal swelling, already well substantiated in their use, clearly indicates the value of that supplementary route. ${ }^{114}$ is

Figure 3: Results of Fisher's least significant difference multiple comparison tests for significant differences among pairs of mean responses (population values from Table I) to nine corneal exposure conditions, ranging from no lens present and the eye continuously exposed to air (approximately 155 mm $\mathrm{Hg} \mathrm{PO}_{2}$ ), through interblink intervals with an oxygen impermeable lens in place of 1 to 7 seconds, and for 300 seconds (that is, with the lens remaining statically on the open eye surface without a blink over those periods). At each interblink interval any two means not covered by the same line segment are significantly different.
This study was supported by a grant from the National Institutes of Health, EYO2382, to R M Hill.

1 Holden BA, Mertz GW. Critical oxygen levels to avoid corneal edema for daily and extended wear contact lenses. Invest Ophthalmol Vis Sci 1984;25: 1161-7.

2 Holden BA, Sweeney DF, LaHood D, Kenyon E. Corneal deswelling following overnight wear of rigid and hydrogel contact lenses. Curr Eye Res 1988; 7: 49-53. 
3 Hill RM, Fatt I. Oxygen depletion of a limited reservoir by human conjunctiva. Nature 1963; 200: 1011-2.

4 Fatt I, Hill RM, Takahashi GH. Carbon dioxide efflux from the human cornea in vivo. Nature $1964 ; 203: 738-40$.

Carney LG, Hill RM. Human tear pH. Arch Ophthalmol 1976; 94: 821-4.

6 Carney LG, Hill RM. Human tear buffering capacity. Arch Ophthalmol 1979; 97: 951-2.

7 Benjamin WJ, Hill RM. Human tears: osmotic characteristics. Invest Ophthalmol Vis Sci 1983; 24: 1624-6.

8 Benjamin WJ, Hill RM. Human cornea: oxygen uptake immediately following graded deprivation. Graefs Arch Clin Exp Ophthalmol 1985; 223: 47-9.

9 Benjamin WJ, Hill RM. Human corneal oxygen demand: the closed eye interval. Graefes Arch Clin Exp Ophthalmol 1986; 224: $291-4$.
10 Benjamin WJ. Corneal physiology under the closed eyelid of humans. Thesis. Ohio State University, 1982.

$11 \mathrm{Ott} \mathrm{L}$. An introduction to statistical methods and data analysis. Massachusetts: Dunbury, 1977: 384-8.

in WJ, Hill RM. Human cornea: individual responses . to hypoxic environments. Graefes Arch Clin Exp Ophthalmol

13 Carney LG, Hill RM. The nature of normal blinking patterns Acta Ophthalmol (Kbh) 1982; 60: 427-33.

14 Holden BA, Sweeney DF, Sanderson G. The minimum precorneal oxygen tension to avoid corneal edema. Inves Ophthalmol Vis Sci 1984; 25: 476-80.

15 Stocker E, Schoessler JP. Corneal endothelial polymegathism induced by PMMA contact lens wear. Invest Ophthalmol Vis Sci 1985; 26: 857-63. 